\title{
Relações Sociais no Setor de Cama \& Café em Parintins na Amazônia: uma perspectiva com base nas análises de redes sociais
}

\author{
The Social Relations in Bed and Breakfast industry in Parintins Amazon: \\ a perspective based on social network analysis
}

\section{Las relaciones sociales de la Industria de alojamiento y desayuno en Parintins Amazon: una perspectiva basada en el análisis de redes sociales}

\author{
Paulo Augusto Ramalho De Souza ${ }^{1}$ \\ Milton Carlos Farina ${ }^{2}$ \\ Claudia de Oliveira Costa3 \\ Antonio Sergio da Silva ${ }^{4}$ \\ Maria do Carmo Romeiro ${ }^{5}$
}

\begin{abstract}
Resumo: A atividade turística é de relevante importância para a economia de municípios da Amazônia como é o caso de Parintins. Devido à importância dos diferentes setores da atividade turística esta pesquisa buscou descrever por meio da metodologia de Análise de Redes Sociais as interações entre agentes da Associação dos Proprietários do Projeto Cama \& Café - ACAMPIN. Para tal, foi realizado um estudo exploratório com aplicação de questionários junto a 15 proprietários de Cama \& Cafés associados à ACAMPIN. Como metodologia de análise foi utilizada a técnica de Análise de Redes Sociais por meio dos com os softwares Ucinet 6.232 e NetDraw 2.089. As análises identificaram a centralidade de alguns agentes da rede como o proprietário identificado pela sigla CC14 e a o poder de intermediação do agente CC12 o que pode conferir aos mesmos um papel estrategicamente relevante na transmissão e retenção de informações importantes para o desenvolvimento da rede de Cama \& Café local. Por fim a pesquisa identificou a importância de aprofundamento em outras medidas de Análises de Redes Sociais que possam
\end{abstract}

1 Graduado e Mestre em Administração na Universidade Federal de Mato Grosso do Sul- UFMS. Doutorando em Administração na Universidade Municipal de São Caetano do Sul - USCS. Professor do Departamento de Administração Universidade Federal de Mato Grosso - UFMT. E-mail: pauloramalho@cpd.ufmt.br

2 Doutor em Administração pela USP e Professor do programa de pós graduação em administração da Universidade Municipal de São Caetano do Sul - USCS. E-mail: milton_farina@uol.com.br

3 Graduada e Professora de Administração pela Universidade Federal do Amazonas - UFAM.E-mail: klaudynha_costa@hotmail.com

4 Mestrando em Administração pela Universidade Municipal de São Caetano do Sul USCS. E-mail: hijjala@gmail.com

${ }^{5}$ Doutora em Administração pela USP e Professora do programa de pós graduação em administração da Universidade Municipal de São Caetano do Sul - USCS. E-mail: mromeiro@uscs.edu.br 
descrever outras dimensões não abordadas nesta pesquisa ou até mesmo a inferência de agentes externos à rede Cama \& Café do município de Parintins AM que possam influenciar no transito das informações dentro da rede.

Palavras Chave: Cama \& Café; Análise de Redes Sociais; Atividade Turística.

Abstract: Tourist activity is of key importance for the economy of the municipalities of the Amazon such as Parintins. Due to the importance of the different sectors of tourism this study sought to describe the methodology by means of Social Network Analysis of the interactions between agents Owners Association Project Bed and Breakfast - ACAMPIN. To this end, we conducted an exploratory study with application of questionnaires to 15 owners of Bed and Breakfast's associated ACAMPIN. The methodology of analysis technique was used for analysis of social networks through software with Ucinet NetDraw 6,232 and 2,089. The analysis identified the centrality of some agents of the network as the owner identified by the acronym CC14 adn power brokering agent CC12 which can confer the same strategically relevant role in the transmission and retention of important information for the development of the network of Bed \& Breakfast site. Finally, the research identified the importance of deepening in other measures of social network analysis can describe other dimensions not addressed in this research or even inference agents external to the $B \& B$ network in the city of Parintins in Amazon that can impact the transit of information within the network.

Keywords: Bed and Breakfast; Social Network Analysis; Tourist activity.

Resumen: La actividad turística es de importancia clave para la economía de los municipios de la Amazonia, como Parintins. Debido a la importancia de los diferentes sectores del turismo Este estudio trata de describir la metodología por medio de análisis de redes sociales de las interacciones entre los agentes de la Asociación de Propietarios del Proyecto Bed and Breakfast - ACAMPIN. Con este fin, se realizó un estudio exploratorio con aplicación de cuestionarios a 15 propietarios de la cama y del desayuno ACAMPIN asociada. La metodología de la técnica de análisis se utilizó para el análisis de las redes sociales a través de software con Ucinet NetDraw 6232 y 2089 . El problema análisis identificó la importancia de algunos agentes del propietario de la red al problema identificado por las siglas CC14 CC12 agente de intermediación de energía adn puede conferir la que el mismo papel estratégicamente importante en la transmisión y conservación de información importante para el desarrollo de la red de Bed \& Breakfast sitio. Por último, el problema de investigación identificó la importancia de profundizar en otras medidas de análisis de redes sociales no pueden describir otros aspectos abordados en esta investigación, o incluso agentes de inferencia externa a la red de B \& B en la ciudad de Parintins en Amazon Que puede afectar el tránsito de la información dentro de la red.

Palabras-clave: Alojamiento y desayuno, análisis de redes sociales, la actividad turística.

\section{INTRODUÇÃO}

A atividade turística engloba a combinação de diferentes setores e empresas, sendo, transportes, alojamento, serviços de alimentação, lojas, espetáculos, instalações para atividades diversas e outros serviços receptivos disponíveis para indivíduos ou grupos que viajam ou que saem de casa para desfrutar de algum tipo de lazer (Beni, 2001). Do ponto de vista econômico, pode-se dizer que é a soma total dos gastos com deslocamento e entretenimentos de pessoas dentro e fora de um país. 
Dentre as atividades econômicas de um país, o turismo apresenta-se como um dos fenômenos mais relevantes, dinâmicos e complexos, isso se dá em virtude de seu efeito direto no desenvolvimento econômico, social, político e ambiental nas regiões nas quais está inserido (Montanari \& Giraldi, 2013).

A atividade do turismo é tida pelos governantes de países em desenvolvimento como uma importante ferramenta para o incremento da economia. Isso devido ao setor possuir um relevante papel como irradiador de divisas para diferentes camadas sociais, tanto para a iniciativa privada quanto para o setor público, sendo notável a ampla capacidade de gerar renda, trabalho e tributos se comparado com outros setores da economia (Souza \& Anjos, 2012).

O turismo passou a ser considerado estratégico, pois está direcionado para o alcance dos objetivos nacionais, contribuindo para o desenvolvimento do país, para a diminuição de desequilíbrios regionais, geração de emprego e renda, divulgação da sua imagem externa, ingresso de divisas estrangeiras e a melhoria dos serviços de infraestrutura básica.

No Brasil, a atividade turística apresenta-se em uma curva ascendente, a soma das riquezas produzidas pelo setor, no ano de 2011, superou os $\mathrm{R} \$ 1,4$ bilhões, sob a ótica da oferta, totalizando cerca de $3,6 \%$ do PIB brasileiro (IBGE, 2012). Tais informações descrevem a importância econômica da atividade turística.

No município de Parintins, onde o turismo movimenta milhões de reais devido a Festa Folclórica dos Bois Garantido e Caprichoso que tomou proporções internacionais e projetou Parintins para o mundo, o espírito empreendedor foi despertado nos agentes locais e atraiu consequentemente a atenção de investidores (AMAZONASTUR, 2009).

A atividade turística na região de Parintins para alguns autores (Souza, Andrade \& Cordeiro, 2012) está relacionada com a interação e as trocas entre as instituições locais (Instituições Financeiras, Universidades, Estado, Instituições Apoiadoras, Instituições Culturais e Religiosas, Associações, Cooperativas e Iniciativa Privada).

Nesse contexto, a busca pelo estabelecimento de processos eficazes é fundamental para manter a competitividade, não somente das empresas locais, mas também do sistema econômico em geral, onde se inclui o setor turístico. Este cenário demanda estruturas diferenciadas para o entendimento dos fluxos e interações dos atores do meio, como a metodologia de Análise de Redes Sociais, a qual tem sido utilizada com o intuito de entender esta dinâmica (Flecha et al., 2012).

As redes de atores locais reúnem indivíduos e instituições, de maneira participativa, em torno de causas afins com atuações colaborativas e/ou cooperativas que são sustentadas pela vontade e pela afinidade de seus integrantes (Oliveira \& Cândido, 2006).

O perfil dos agentes presentes nas redes de atores locais difere em cada sociedade. Para tal, torna-se necessário a utilização de mecanismos que auxiliem no entendimento das trocas entre os agentes e as externalidades geradas neste processo, Marteleto (2001) destaca que a utilização de Análise de Redes Sociais em conjunto com técnicas de interpretação de dados qualitativas contribui para este processo. 
Tal temática é de fundamental importância para o setor turístico e consequentemente para a economia de estados e cidades desprovidas de um centro financeiro próprio, que precisam de meios secundários para seu empoderamento econômico.

O setor turístico em Parintins AM, foco deste estudo, possui relevante importância para a irradiação de recursos na economia local. O setor de Cama \& Café pode ser considerado um exemplo de atividade que agrega um conjunto de atores individuais no qual o aporte de recursos financeiros está relacionado com o empoderamento econômico, em virtude das características individuais de seus atores (Hsieh \& Lin, 2010).

No munícipio de Parintins AM, reconhecido como um dos mais importantes roteiros turísticos da região norte do Brasil, o setor de Cama \& café por meio da Associação dos Proprietários do Projeto Cama e Café - ACAMPIN, fundada em 2001 e com cerca de 25 famílias envolvidas, apresenta-se como o mais relevante setor do hospedagem local (Souza, Andrade \& Cordeiro, 2012).

Neste contexto, o entendimento das interações nas redes de atores locais pode colaborar com o desenvolvimento de politicas para a atividade turística. O questionamento a ser respondido consiste em: como acorrem as interações entre os agentes da Associação dos Proprietários do Projeto Cama e Café - ACAMPIN, com foco no empoderamento dos atores locais envolvidos na atividade turística do município de Parintins AM?

Como objetivo geral esta pesquisa busca descrever por meio da metodologia de Análise de Redes Sociais as interações entre agentes da Associação dos Proprietários do Projeto Cama e Café - ACAMPIN.

\section{A ATIVIDADE TURÍSTICA}

No início do século XX surgiram as primeiras tentativas de conceituação de turismo, a partir da qual surgiram as diversas definições que se tem atualmente na literatura.

Em 1911 Hermann von Schullern zu Schattenhofen escreveu que turismo compreende todos os processos, especialmente os econômicos, que se manifestam na chegada, na permanência e na saída do turista de um determinado local (Wahab, 1991). Esta definição focada na economia explica-se pelo fato deste autor ser economista.

Assim, o conceito de turismo é muito abrangente e na realidade não existe um único e verdadeiro conceito, uma vez que apresenta diversas concepções que estão relacionadas com a abordagem de cada autor. Mas da definição acima apresentada, nota-se, a freqüência das seguintes variáveis: tempo de permanência, a visita sem fins lucrativos e a livre escolha. Além das variáveis, temos os elementos que compõe esta atividade intangível, que são: os turistas, o espaço geográfico e os negócios e instituições.

Com base nestas informações podemos dizer que o turista é o principal ator, pois é este que direciona seu tempo para fazer outra atividade não remunerada por um tempo finito em um local, ou seja, o espaço geográfico receptor ou gerador do trânsito. E para que as atividades 
turísticas, ou produtos turísticos ocorram é necessário haver um suporte por parte das instituições.

Além da relevância institucional é importante ressaltar outras áreas que influenciam diretamente na atividade turística. Conforme Figuerola (1985) esses áreas são: política, legal, econômica, tecnológica, ambiental e social.

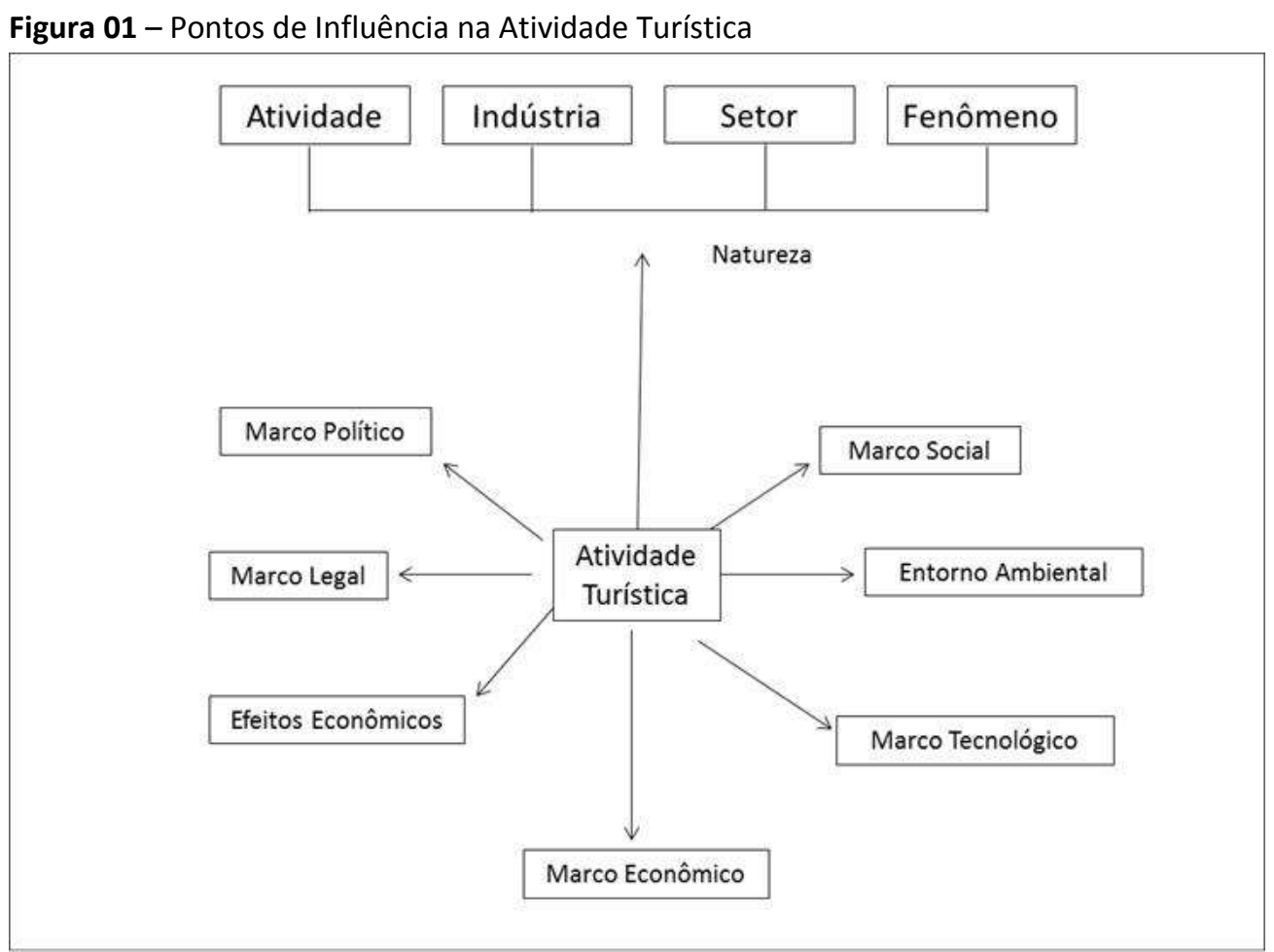

Fonte: Adaptada de Figuerola (1985)

A partir da Figura 1 observa-se a atividade turística como um sistema que esta relacionada com vários setores da sociedade, como a parte legal, a política, a tecnológica entre outros, que estão presentes no meio local.

O marco social engloba o comportamento coletivo, níveis culturais, estrutura familiar, tipos de habitat, tradição de viagens, pressão de propagandas e religiosidade. Estes fatores darão a sinalização de qual tipo de atividade deve ser estimulada e a vocação de determinado local.

Associado ao marco social tem-se o marco político, o qual engloba as doutrinas políticas, ócio, objetivos do Estado, as tensões políticas e os conflitos de trabalho. Esses fatores impactam diretamente na escolha do destino, na permissão ou não para viajar para o exterior. Ademais, o marco político atua fortemente incentivando e apoiando a expansão do turismo como atividade de cunho econômico e social.

O marco ambiental leva em consideração as condições naturais, genéricas, meio urbano, níveis de contaminação, níveis de receptividade e recursos necessários como água e energia. Este pode ser visto como o cerne do turismo, pois a busca do espaço natural ou do construído (urbano) 
desde que exista equilíbrio ambiental e patrimonial é um ponto de atração.

A tecnologia se expressa pelo desenvolvimento dos transportes, materiais de construção, desenvolvimento das comunicações e da informática. O desenvolvimento tecnológico estimula o desejo por locais mais distantes. No âmbito econômico tem-se a evolução do PIB da região, o comportamento da distribuição de renda, índices de preços, níveis de inversão (investimentos), propensão ao desenvolvimento e ao consumo.

O marco jurídico compõe junto com os órgãos públicos o ambiente institucional, pois é este que limitará ou facilitará a expansão da atividade turística, a qual se origina e se caracteriza por ser uma relação de consumo. Pela ótica econômica, trata-se de uma relação de compra e venda que deve ser mediada pelas forças de mercado, mais especificamente, as instituições.

\section{O CAMA \& CAFÉ COMO MEIO DE HOSPEDAGEM}

As discussões relacionadas ao setor extra-hoteleiro por meio da pesquisa de Montejano (2001, p. 161) pode ser definido como "estabelecimentos mercantis que prestam diversos tipos de alojamentos distintos dos que oferecem os hotéis, devido à sua diferente ordenação legal, de infraestrutura, preços e serviços".

Beni (2001) menciona como meios de hospedagem extra-hoteleiros alguns estabelecimentos, sendo pensão, pensionato, colônia de férias, acampamento turístico, imóvel locado, segunda residência e aos leitos avulsos em casas de família que são as características das pousadas associadas à ACAMPIN em Parintins AM.

A hospedagem domiciliar ou Cama \& Café, termo traduzido do conceito inglês bed and breakfast, é apresentada por Pimentel (2009) como opção de meio de hospedagem na qual o turista tem acesso a um quarto para passar a noite com café da manhã incluso.

Os quartos para passar a noite em casas de família, também denominados Cama \& Café (B\&B) são relevantes quando se discute o turismo rural, contribuindo de maneira efetiva com a inovação setorial, mesmo que em pequena escala. Alguns autores (Hjalager, 1996, Hsieh \& Lin, 2010) citam como potencialidades o uso de instalações diferenciadas para pousadas e o fomento a discussões relacionadas com a sustentabilidade.

O setor de Cama \& Café confere à diversidade a atividade turística de uma região e fomenta o apelo da comunidade local junto aos turistas em virtude de suas características individuais, propiciando-lhes um ambiente amigável que estimule sua ligação com o meio local, por meio de seus aspectos culturais e ecológico-naturais (Nuntsu et al., 2004).

As características locais e culturais apresentam-se como parte do produto hospedagem no setor de Cama \& Café. O perfil das famílias, estilo de vida e as características físicas sociais das residências familiares conferem ao turista um espaço único de pertencimento à "identidade local" (Mascarenhas \& Flecha, 2006).

O efeito econômico do setor de Cama \& Café pode ser considerado substancialmente positivo, principalmente quando visualizado em comunidades menores, onde motéis e hotéis são 
limitados e as casas de família podem absorver um grande percentual de visitantes (Zane, 1997). No município de Parintins o setor de cama \& café propicia a sustentabilidade por auferir aos atores locais a possibilidade de ganhos financeiros por meio de sua inserção da atividade turística.

\section{ANÁLISE DE REDES SOCIAIS}

Uma rede pode ser definida para Marteleto (2001) como um conjunto de atores que compartilham valores e interesses comuns em um espaço determinado, configurando um conjunto de atores autônomos e interligados simultaneamente. Na atividade turística a dinâmica dos empreendimentos apresenta inter-relação entre os diferentes atores e agentes locais.

Uma rede pode ser considerada um conjunto de nós conectados por meio da interação e do conjunto de regras presentes no grupo. As redes são organismos abertos capazes de expandirem-se de maneira ilimitada, agregando novos nós, desde que os mesmos consigam se inserir na dinâmica da rede (Costa, 2003).

Conforme Flecha, et al. (2012), que estuda o desenvolvimento e implementação de redes no âmbito da atividade turística, uma rede segue a seguinte configuração estrutural:

O surgimento de uma rede ocorre quando um proposito comum consegue aglutinar diferentes atores e convocá-los para a ação. É uma organização sem hierarquia, os seus elementos estão ordenados sem a mediação de qualquer controle ou governo. Essa ordem é produzida por uma dinâmica de auto ajuste, que acontece devido à circulação da informação de modo não linear.

Dentre as diferentes configurações de técnicas de análise de redes, a utilização da Social Network Analysis ou Análise de Redes Sociais, mede os relacionamentos na rede por meio de uma escala binária ou de valor. Essas medidas podem ser simplesmente indicadas por 0 ou 1 ( 0 = Não tem relacionamento ou 1= Possui relacionamento), podendo ser útil quando o pesquisador estiver mapeando redes de grandes organizações (Hatala, 2006).

A utilização da técnica de Análise de Redes Sociais tem despertado o interesse de pesquisadores de diferentes áreas, pois os mesmos tentam entender o efeito da organização da rede na vida social dos atores envolvidos. Essa demanda deu origem a diversas técnicas de análise que têm como base as relações entre os indivíduos, em uma estrutura em forma de rede (Marteleto \& Silva, 2004).

Hanneman (2005) apresenta uma técnica da análise de redes que busca o entendimento da centralidade e do poder de atores em uma rede e as suas identificações, serão utilizadas as seguintes medidas, sendo elas:

- Degree Centrality: esta medida identifica os atores que possuem mais vínculos com outros atores, e por esta razão podem auferir ganhos por suas posições favorecidas. Em virtude do maior número de laços dentro da rede, estes atores podem utilizar de mecanismos alternativos para satisfazer suas necessidades e, 
portanto, são menos dependentes de outros indivíduos. Segundo o autor esta é uma medida muitas vezes eficaz de centralidade de um ator.

- Closeness Centrality: a medida de centralidade que analisa a proximidade busca descrever a distância de um ator para todos os outros da rede. Essa medida vai além do entendimento do grau da centralidade, pois busca analisar, também, todos os laços indiretos de um determinado ator com a rede.

- Betweenness Centrality: essa medida busca identificar na rede os atores com maior poder de intermediação de informações. Por exemplo, para uma informação chegar a um determinado ator ela necessita passar por um intermediário. Assim, um determinado ator pode atrasar, ou até mesmo evitar o trânsito de uma informação. isso fornece aos atores que se encontram "entre" os demais o poder da governança das relações.

\section{PROCEDIMENTOS METODOLÓGICOS}

Esta pesquisa utilizou de uma estrutura metodológica de cunho exploratório com método de abordagem dedutivo, visto que parte de uma visão geral da literatura aqui selecionada referente ao turismo, a estrutura dos projetos de Cama \& Café e a Análise de Redes Sociais, para entender as relações entre os atores do setor no município de Parintins AM.

A pesquisa buscou inferir todos os associados à ACAMPIN (população de 25 hospedagens domiciliares), entretanto apenas 15 atores associados responderam o estudo, sendo que os não respondentes foram desconsiderados para a estruturação da rede de interações local. A pesquisa de campo foi realizada nos meses de abril e maio do ano de 2013.

$\mathrm{O}$ instrumento de coleta de dados utilizado foi o questionário estruturado com perguntas fechadas, com o intuito de identificar a profundidade das relações dos atores locais envolvidos na associação de Cama \& Café local.

Neste cenário de relevantes relações locais, como método de análise dos dados tomou por base as orientações da teoria de Análise de Redes Sociais com foco em três medidas de centralidade, sendo elas, Degree que buscou identificar os atores dentro da rede de Cama \& Café com mais vínculos de inter-relação; Closeness com o intuito de descrever os atores com mais proximidade do conjunto de atores locais; e por fim a medida conhecida como Betweenness que tem como foco identificar os atores na rede da ACAMPIN que mais intermediam as informações presentes na rede (Hanneman, 2005).

Como ferramenta de análise, foram utilizados o software Ucinet 6.232 For Windows com o intuito de obter o desenho da rede, descrição de suas propriedades e a análise do comportamento dos atores locais do setor de Cama \& Café que compõem a rede. Por fim, a utilização do software NetDraw 2.089, para obter as imagens da rede local (Hanneman, 2005).

\section{ANÁLISE E DISCUSSÃO DOS DADOS}


O município de Parintins é composto aproximadamente por 68.033 hab. na área urbana e 38.000 hab. na área rural, fazendo um total de 106.033 habitantes (IBGE, 2010). O Festival Folclórico de Parintins é uma festa popular realizada anualmente no último fim de semana de Junho na cidade de Parintins, onde competem duas agremiações folclóricas o Boi Garantido e o Boi Caprichoso.

Além do Festival Folclórico, o município possuí outras opções de lazer, especialmente aquelas ligadas aos balneários localizados em rios, lagos e igarapés. No rio uaicurapá, na época da vazante, surgem às belas praias fluviais muito procuradas pelos banhistas, como também as ilhas do pacoval, das onças do marinho e das guaribas, ricas em fauna e flora. Para os apreciadores da pesca esportiva, as opções também são variadas. Macurany, Aninga, Parananema, Zé Açu, Valéria e Uaicurapá são alguns dos lagos mais visitados da região (AMAZONASTUR, 2009).

Contudo, esta demanda turística é acolhida em sua maioria, pela rede de Cama \& Café da associação ACAMPIN, que apresenta um conjunto de diferentes atores que possuem pequenos empreendimentos que oferecem hospedagem familiar.

A estrutura dos Cama \& Cafés em sua maioria é composta por quartos que foram construídos em conjunto com a residência dos proprietários ou em alguns casos pequenas edificações desmembradas, porém no mesmo terreno.

Os atores da rede de Cama \& Café trocam diferentes tipos de informações em seu cotidiano como a transferência ou existência de vagas para um hóspede, aquisição de itens para seu empreendimento, informações sobre linhas de financiamento, cursos e treinamentos, questões relacionadas às Associações Folclóricas, dentre outros fatores presentes na dinâmica local.

Com a aplicação dos questionários e por meio das repostas dos 15 atores associados à ACAMPIN, que para afeito da pesquisa serão denominados respectivamente de (CC = Cama e Café) CCO1 até CC15.

A Figura 02 apresenta o grau de centralidade da rede de Cama \& Café foco do estudo. 
Figura 02 - Degree A centralidade na rede de Cama \& Café

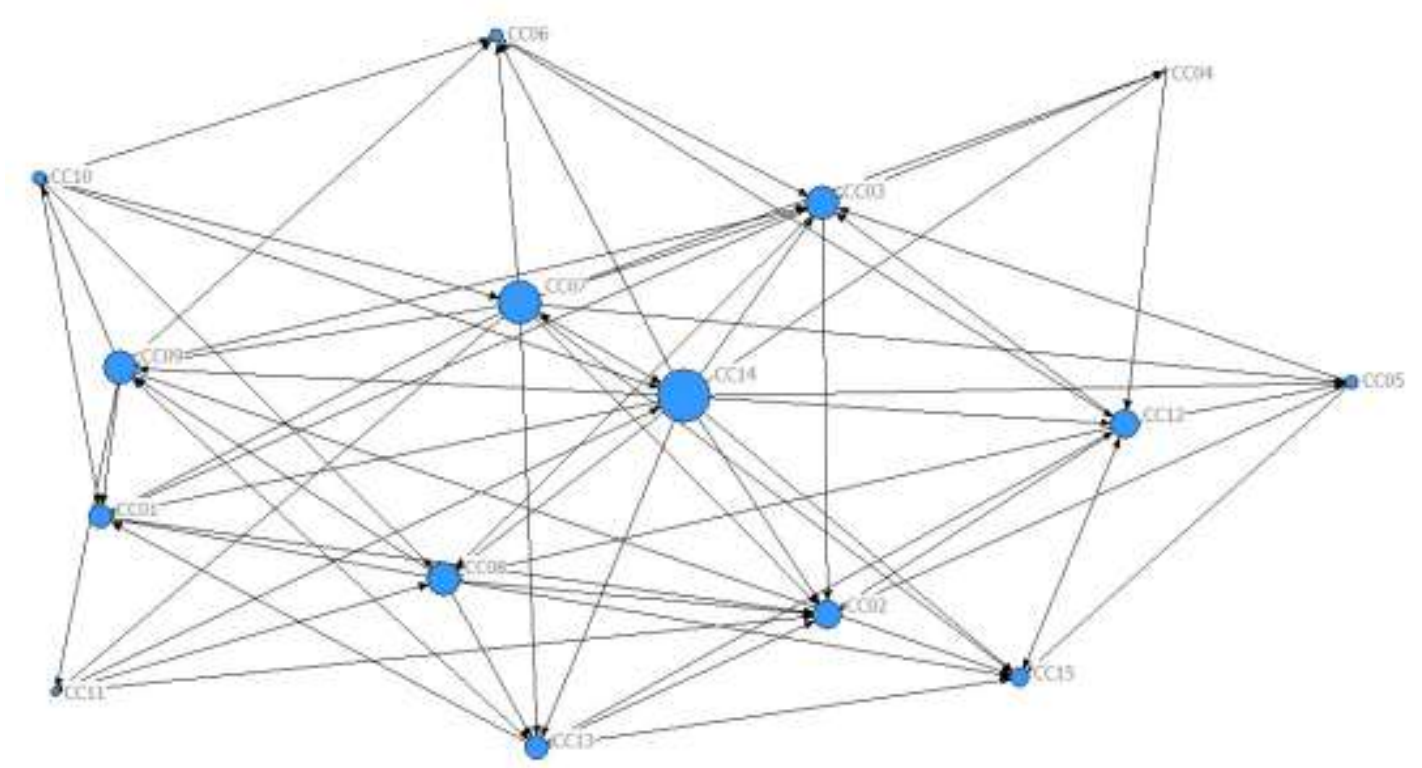

Fonte: Elaborado pelos autores com base na pesquisa de campo

Legenda: Quanto maior o CC maior a centralidade de informação no Cama e Café do município

Um ator é entendido como central em uma rede social, quando o mesmo em virtude de seu posicionamento, recebe dos demais atores da rede, fluxos de informações que o tornam estratégico para realização de ações nesta determinada rede.

$\mathrm{Na}$ rede social da ACAMPIN, por meio da Figura 02 percebe-se que o agente mais central na rede de relações são CC14 e o CC07, os atores apresentam-se como mais centrais na rede tendo relações com praticamente todos os demais atores presentes no meio. Inversamente o CCO4 apresenta como agente menos central frente aos demais atores, com uma baixa interação dentro da rede.

$\mathrm{O}$ alto índice de centralidade dos atores CC14 e CC07 (estando ligados respectivamente com 14 e 11 dos 15 Cama \& Cafés da rede) frente à transferência de informação na rede o torna de relevante importância na implementação de ações relacionadas com desenvolvimento do setor em Parintins AM. Seja pela comunicação de ações locais ou até mesmo no apoio da implementação de capacitações ou formações relacionadas com o turismo.

A Figura 03 Apresenta as distâncias (Closeness Centrality) de um ator em relação a todos os outros por meio das somas das distâncias geodésicas (menor distância entre todos os atores). 
Figura 03- Closeness - A proximidade do conjunto de atores locais na rede de Cama \& Café

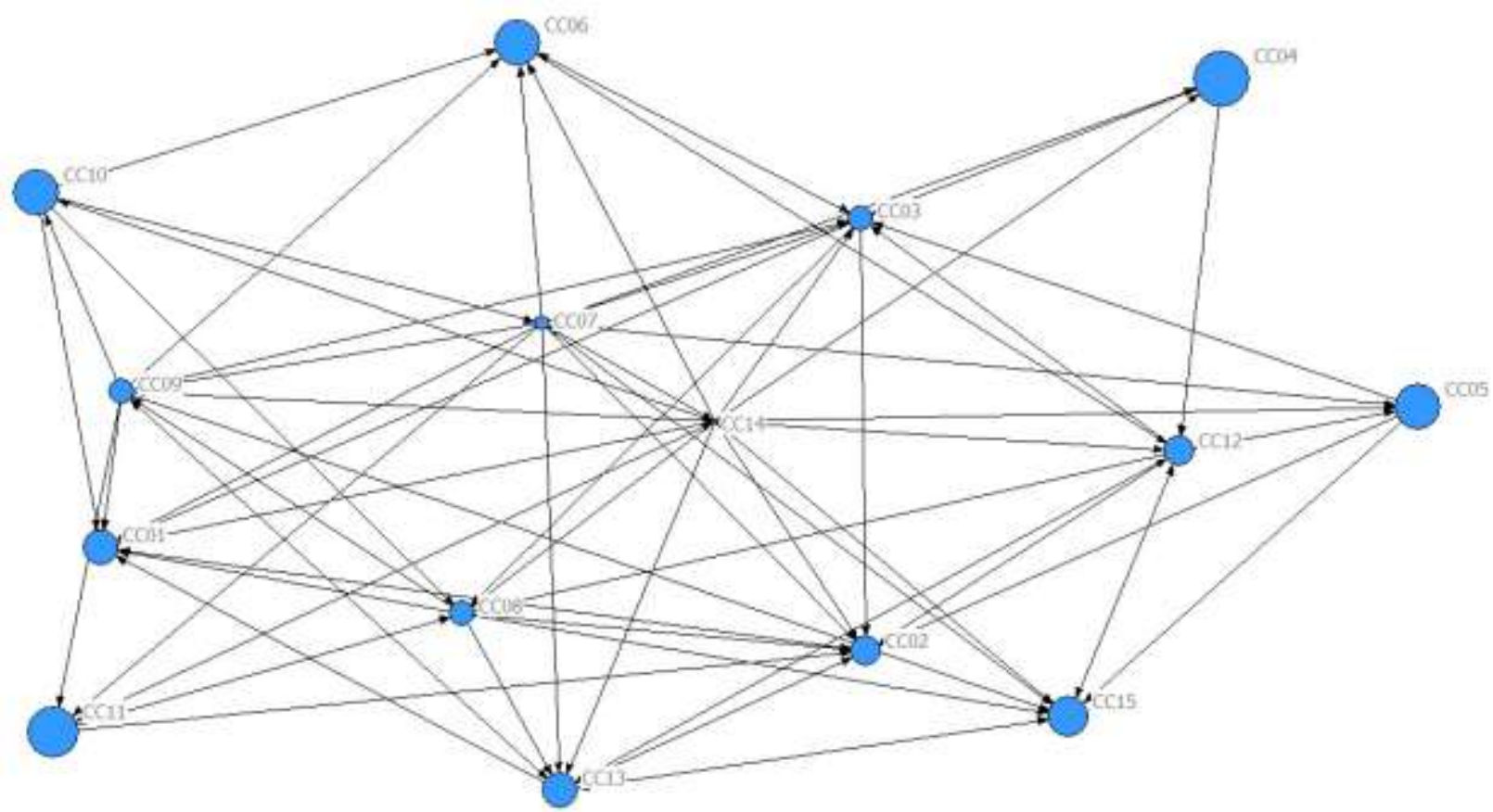

Fonte: Elaborado pelos autores com base na pesquisa de campo

Legenda: Quanto maior o CC maior menor é seu poder de intermediar as informações no Cama e Café do município

Com foco em identificar a centralidade de proximidade dentro da rede e respectivamente o poder exercido pelos domais atores da rede sobre cada ator individualmente. Esta avaliação se faz importante à medida que apresenta os atores que menos influenciam na dinâmica das informações na rede.

Pode-se destacar na Rede Social da ACAMPIN, por meio da Figura 03, que os atores CC04 e CC11 possuem maior distância da centralidade da rede e menor influência no transito das informações. Esses atores segundo a Análise de Redes Sociais se caracterizam por possuir pouca afinidade com os demais atores da rede, possuindo poucas relações quanto à troca de informação sobre a dinâmica do turismo local.

A Figura 04 apresenta a medida de centralidade de intermediação de informações na Rede Social da ACAMPIN.

Figura 04 - Betweeness - Intermediação de Informação na rede de Cama e Café 


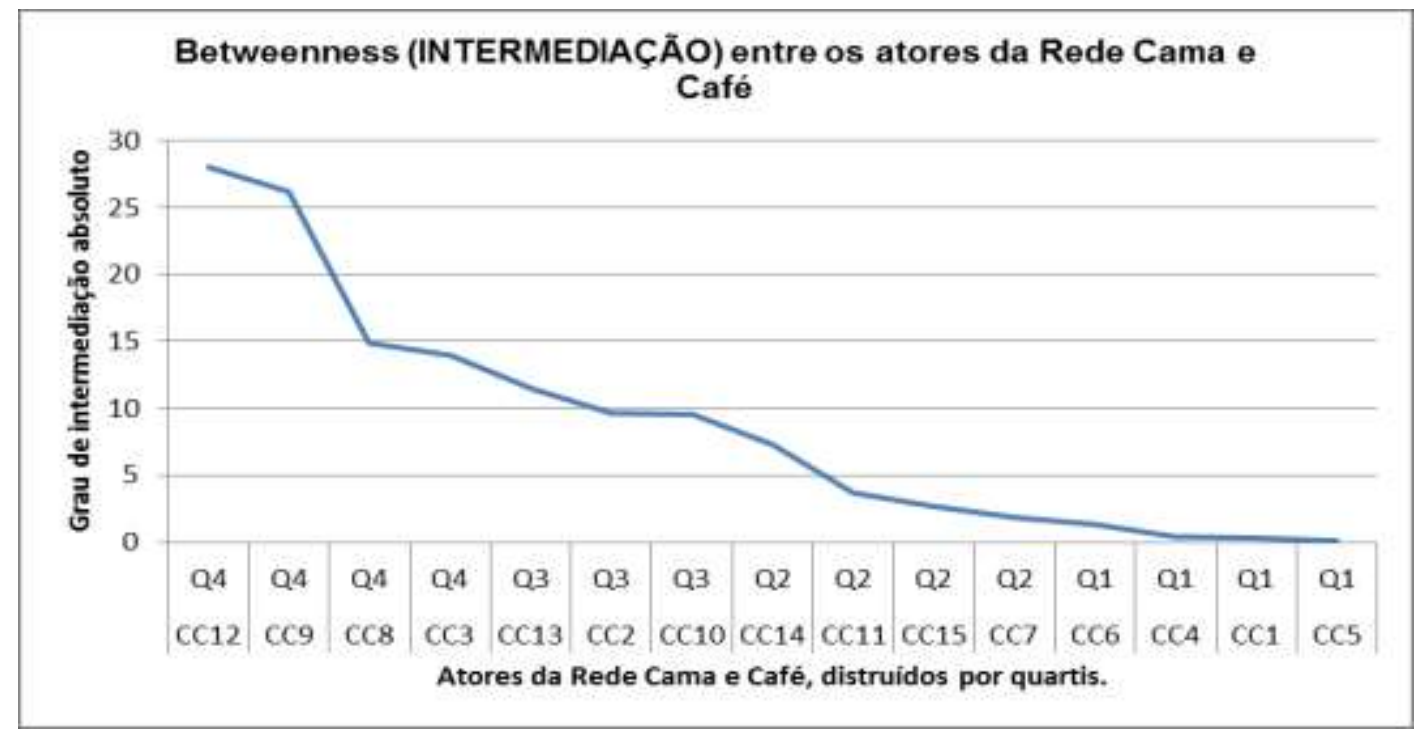

Fonte: Elaborado pelos autores com base na pesquisa de campo

A medida de centralidade de intermediação de informações em uma rede social apresenta a capacidade que um determinado ator possui de ligação frente aos demais atores da rede social. A identificação é estratégica, pois o mesmo pode auxiliar no fluxo de informação em uma rede social como a de Cama \& Café de Parintins AM.

Por meio da análise da Figura 04 percebe-se que a função de mediador na rede em Parintins AM pode conferida para os atores CC12 e CC09, isso ocorre se da por serem reconhecidos no município por estarem na atividade a um longo e no caso do ator CC12 o mesmo também possuí outros empreendimentos sendo de uma família tradicional na região.

A análise dos quartis da Figura 04 demostra o quão concentradas são as intermediações de informações na rede de Cama \& Café em Parintins AM, na qual 04 atores (CC12,CC09,CC8 e CC3) concentram grande parte das intermediações presentes na rede local.

A Tabela 01 apresenta os dados das análises do software Ucinet e adaptada a uma forma matricial, apresentam-se os valores métricos básicos da rede, na qual os principais atores de cada medida já foram apresentados nas Figuras 02,03 e 04.

Tabela 01 - Valores Métricos Básicos da Rede Social da ACAMPIN 


\begin{tabular}{lccc}
\hline Atores & Degree & Betweeness & Closeness \\
\hline CC01 & 1,0 & 0,28 & 20,0 \\
CC02 & 2,0 & 9,68 & 19,0 \\
CC03 & 5,0 & 13,98 & 22,0 \\
CC04 & 2,0 & 0,46 & 31,0 \\
CC05 & 4,0 & 0,09 & 30,0 \\
CC06 & 2,0 & 1,30 & 27,0 \\
CC07 & 11,0 & 1,80 & 50,0 \\
CC08 & 5,0 & 14,84 & 25,0 \\
CC09 & 7,0 & 26,15 & 30,0 \\
CC10 & 5,0 & 9,58 & 40,0 \\
CC11 & 3,0 & 3,75 & 39,0 \\
CC12 & 6,0 & 28,00 & 22,0 \\
CC13 & 4,0 & 11,45 & 23,0 \\
CC14 & 14,0 & 7,32 & 49,0 \\
CC15 & 2,0 & 2,6 & 22,0 \\
\hline
\end{tabular}

Fonte: elaborado pelos autores com base na pesquisa de campo

Por meio da Análise da Tabela 01 pode-se apresentar o desempenho individual de cada cama e café presente na rede a ACAMPIN quais são as mais centrais da rede e quais são os isolados e que muitas vezes necessitam de um trabalho de inserção nesta rede social.

\section{CONSIDERAÇÕES FINAIS}

Por meio da pesquisa pode-se apresentar a importância da atividade turística para o empoderamento financeiro de atores locais, por meio da organização de setores ligados ao turismo com relevante potencial, como é o caso do projeto Cama \& Café para o município de Parintins AM. O projeto por meio da ACAMPIN agrega um conjunto de atores organizados em torno entorno da hospedagem familiar.

Com o intuito de entender a dinâmica do fluxo de informações entre os agentes da rede de Cama \& Café de Parintins AM, o emprego da metodologia de Análise de Redes Sociais nesta pesquisa permitiu descrever elementos que sugerem o modo de comunicação e aprendizado coletivo entre os atores da rede.

Os atores identificados como centrais ou mediadores na rede podem ser de relevante importância para o desenvolvimento de políticas públicas relacionadas com a atividade turística na região, pois os mesmo são responsáveis pela dinâmica e mobilização do fluxo das informações na rede.

Com foco na intermediação das informações pode-se identificar por meio da pesquisa que 
a rede apresenta como agente de maior intermediação entre dos demais atores um dos mais antigos proprietários de Cama \& Café do município, podendo ser caracterizado como detentor do poder de referência em virtude de seu tempo de atividade.

O fato da identificação de uma estrutura de rede muito concentrada em um número pequeno de atores, evidencia uma possível dificuldade na implementação de políticas públicas e de treinamento por meio de instituições públicas e do terceiro setor, pois sem o engajamento de alguns atores centrais estratégicos estas ações podem não surtir efeito ou até mesmo não ter sua disseminação dentro da rede.

Com o desenvolvimento da pesquisa tornou-se importante salientar que as considerações referentes à rede de Cama \& Café de Parintins AM não devem ser tomadas como absolutas, em virtude de algumas limitações que foram identificadas no contexto da pesquisa. A primeira limitação é a incipiente aplicação da técnica de Análise de Redes Sociais no contexto turístico no Brasil. A segunda envolve o fato de que alguns atores não responderam o instrumento de coleta de dados e não puderam ser considerados no contexto da rede.

Por fim a pesquisa identificou a necessidade de aprofundamento no entendimento das interações entre os atores da rede, o que poderia ser sanado tanto pela utilização de outras medidas de Análise de Redes Sociais não utilizadas neste estudo como por novas pesquisas que possam auferir a presença de agentes de outros segmentos da atividade turística que possam influenciar no transito das informações no meio local.

\section{REFERÊNCIAS}

AMAZONASTUR. (2009). Empresa Estadual de Turismo do Estado do Amazonas. Amazonas. Acessado em: 20, Março, 2013 de <http://www.visitamazonas.am.gov.br/site/191081-parintinscurral-de-garantido-e-caprichoso $>$.

Beni, M. C. (2001). Análise estrutural do turismo. São Paulo: Senac.

IBGE. Instituto Brasileiro de Geografia e Estatística. Brasil. Recuperado em 10, Março, 2013 de < http://www.ibge.gov.br/cidadesat/>.

Figueriola, M. P. (1985). Teoria Económica Del Turismo. Madrid: Alianza Editorial.

Flecha, A. C., Castro e Silva, A. V., Fusco, J. P. A. (2012). BERNARDES, Américo Tristão. Redes de empresas e seus efeitos sobre o turismo. RAE-revista de administração de empresas, 52, jul./ago.

Hanneman, R. A. Introduction to Social Network Methods Riverside: University of California, 2005. Acessado em: em 14, Abril, 2013 de < http://faculty.ucr.edu/ hanneman/>.

Hatala, J. P. (2006). Social Analysis in Human Resource Development: A New Methodology. Human Resource Development Review. 5 (1), pp. 49-71. 
Hjalager, A.M. (1996). Agricultural diversification into tourism: evidence of a European community development programme. Tourism Management, 17 (2), pp. 103-111.

Hsieh, Y.C. \& Lin, Y.H. (2010). Bed and breakfast operators' work and personal life balance: a crosscultural comparison. International Journal of Hospitality Management, 29 (4), pp. 576-581.

Marteleto, R. M. (2001). Análise de Redes Sociais: aplicação nos estudos de transferência da informação. Ciência da Informação (Impresso), Brasília, 30(1), pp. 71-81.

Marteleto, R. M. \& Silva, A. B. O. (2004). Redes e capital social: o enfoque da informação para o desenvolvimento local. Ciência da Informação, Brasília, 33, pp. 41-49.

Mascarenhas, M. A. \& Flecha, A. C. (2006). Cama e café: hospitalidade e capital social na preservação do bairro de Santa Teresa, no Rio de Janeiro. Anais do Seminário Internacional sobre Desenvolvimento Regional. Santa Cruz do Sul, RS, Brasil, 03.

Montanari, M. G. \& Giraldi, J. M. E. (2013). Competitividade no Turismo: uma comparação entre Brasil e Suíça. Revista Brasileira de Pesquisa em Turismo, 7, pp. 92-113.

Montejano, J. M. (2001). Estrutura do Mercado Turístico. São Paulo: Roca.

Nuntsu, N., Tassiopoulos. D., Haydam, N. (2004). The bed and breakfast market of Buffalo City (BC) South Africa: present status, constraints and success factors. Tourism Management, 25 (4), $515-$ 522.

Oliveira, V. M. \& Cândido G. A. (2006, outubro). As Formas de Organizações em Redes e a Atuação dos Brokers. Anais do ENCONTRO NACIONAL DE ENGENHARIA DE PRODUÇÃO - ENEGEP. Fortaleza, CE, Brasil, 12.

Pimentel, A. B. (2009). Dádiva e hospitalidade no sistema de hospedagem domiciliar. In: BARTHOLO, R.; SANSOLO, D. G.; BURSZTYN, I. (Orgs.). Turismo de base comunitária: diversidade de olhares e experiências brasileiras. Rio de Janeiro: Letra e Imagem.

Souza, P. A. R. \& Anjos, Y. W. S. (2012). O Desenvolvimento dos Empreendimentos Turísticos da Região de Parintins no Amazonas: uma abordagem relacionada ao estudo de competitividade dos 65 destinos indutores do desenvolvimento turístico regional. Turydes, 5 (12), pp. 3-19.

Souza, P. A. R., Andrade, F. A. V., Cordeiro, K. W. (2012). Os impactos da organização do ambiente institucional no desenvolvimento do arranjo produtivo local do município de Parintins na Amazônia. Pasos (El Sauzal), 10, pp. 563-573.

Wahab, S. A. (1991). Introdução à Administração do Turismo: alguns aspectos estruturais e operacionais do turismo internacional. São Paulo: Pioneira.

Zane, B. (1997). B\&B guest. Cornell Hotel \& Restaurant Administration Quarterly, 38 (4), pp. 69-75.

Artigo recebido em: 22/06/2013. 
